\title{
Working in Unfamiliar Territory: A Rhetorical Criticism of the Work-Related Sequences in The Arrival by Shaun Tan
}

\author{
Andrew Albritton, PhD
}

Missouri State University, USA

Doi: 10.19044/1lc.v8no1a1

URL:http://dx.doi.org/10.19044/1lc.v8no1a1

Submitted: 21 January 2021

Accepted: 12 March 2021

Published: 31 March 2021
Copyright 2021 Author(s)

Under Creative Commons BY-NC-ND

4.0 OPEN ACCESS

\begin{abstract}
:
Shaun Tan's 2006 wordless graphic novel The Arrival presents readers with an affecting portrait of the immigrant experience. Drawing from semiotic theory and the narrative paradigm, this paper offers a rhetorical criticism of the scenes in The Arrival related to the main character's employment-related experiences. The paper proposes a novel theoretical concept - a semiotics of unfamiliarity - and, guided by this concept and the narrative paradigm, concludes that The Arrival is an effective rhetorical artifact that poignantly presents important information about the professional difficulties faced by immigrants. It is recommended that The Arrival be considered for use in organizations that employ newly arrived immigrants.
\end{abstract}

Key Words: Immigration, immigrants, semiotics, narrative paradigm, graphic novels, employment

\section{Introduction}

Immigrants face many potential difficulties as they endeavor to establish themselves in jobs in their new countries (de Castro, Fujishiro, Sweitzer, \& Oliva, 2006; Harrison, Harrison, \& Shaffer, 2019; Valenta, 2008). Some of the work-related difficulties immigrants may experience are poignantly exhibited in Shaun Tan's (2006) wordless graphic novel The Arrival, which relates the tale of an immigrant who moves to an unfamiliar country. The particular brilliance of The Arrival lies in its artful presentation of 
the country to which the immigrant moves: it is a fictional and fantastical place, one in which the flora, fauna, language, and material culture are unlike any on earth. This portrayal of the new home country creates within the reader a sense of wonder and disorientation, thereby encouraging empathy for immigrants who experience strange new lands. Johnston (2012), who investigated the visual communication in The Arrival, notes that "Tan's egalitarian script summons a moral imagination and encourages subjunctive empathies in relation to heterogeneity - empathies that are sorely needed in the 21 st-century world" (437); and Rhoades et al. (2015), in a study of reader experiences of The Arrival, empirically verified that the graphic novel can generate empathic responses. The Arrival's empathy-inducing presentation of potential workrelated problems facing immigrants is analyzed in this paper. It is concluded that The Arrival is rhetorically effective in showing professional difficulties facing immigrants, and it is recommended that employers consider using the graphic novel to improve immigrants' professional experiences.

\section{Methodology}

Foss (2005) posits that the rhetorical criticism of visual artifacts can be inductive or deductive. Inductive criticism evaluates visual artifacts for the purpose of generating or developing theory related to visual rhetoric. Deductive criticism applies established, discourse-based rhetorical theories to visual artifacts. Both approaches are used in this study. First, the work-related scenes in The Arrival are analyzed inductively from a semiotic perspective using concepts from Pierce (1985) and Barthes (1977) for the purpose of proposing a novel theoretical concept: a semiotics of unfamiliarity, according to which icons of unfamiliar things can serve interesting phenomenological purposes. Second, the work-related scenes are analyzed deductively from a narrative paradigm perspective (Fisher, 1978; 1984; 1985a; 1985b; 1989a; 1989b), for the purpose of evaluating whether the scenes operate effectively as rhetorical narratives.

\section{The Artifact}

The Arrival is printed such that it resembles an aged photo album, and the book's sepia toned artwork is reminiscent of antiquated photographs. In the primary narrative of the graphic novel, a man leaves his wife and daughter to travel to a new country. He is perplexed by the culture and natural world of the new country, but, with some adventure, he is able to settle into an apartment and secure a job. Along the way, he is befriended by a kindly animal of a fictional species, and he meets other immigrants who relate their stories of immigration. At the conclusion of the narrative, the man's wife and daughter join him and his animal friend in the new country. In a touching final sequence, the man's daughter goes out to pick up some groceries, and helps another young immigrant find her way through the city. 
The book is divided into six chapters. The fourth chapter deals with the immigrant's work experiences. This chapter opens with the man waking up; eating a breakfast of an unfamiliar vegetable, some of which he shares with his animal friend; dressing for the day; and venturing out into the city with the animal. There are then six panels showing people engaged in a variety of professions. In the first of these panels, men work with poles near large smokestacks. In the second, a man feeds animals of a fictional species. In the third, a woman sells unfamiliar objects. In the fourth, a man works on a device that appears to be an ornamented circle on an axel. In the fifth, a man paints unknown symbols on a wall. And in the sixth, a woman works on a cart topped with a piped device of indefinite purpose. All of these jobs, in will be noted, are to some degree enigmatic, since the reader, like the immigrant, knows very little of the culture of the country.

The immigrant is shown enquiring about jobs with a chef, a mechanic, a shop attendant, and an airfield worker, all to no avail. He has more success when he speaks with a man pasting signage to walls. The man hires the immigrant to continue the work of pasting the signs. The man who hired the immigrant leaves, but returns sometime later to discover that the immigrant who, like the reader, is unfamiliar with the symbols on the signs - is pasting the signs upside down. The immigrant is next hired to deliver goods. The immigrant's new employer shows the immigrant a map and points to the place where the goods should be delivered. The immigrant begins walking in the wrong direction, and is corrected by the new employer. After delivering some packages, the immigrant eventually enters a dangerous area, not noticing some words of warning written beside the area's entrance. (The reader is clued-in to these words of warning by a panel that shows a close-up of some large writing that begins with an inverted exclamation point and ends with an exclamation point and under which is some smaller writing with an arrow pointing to the right.) The man is chased from the area by a humongous, fierce creature that is vaguely avian in appearance.

The immigrant is finally hired to work in a factory, where he stands at a conveyor belt on which handheld objects move by. The purpose and nature of the objects is unclear to the reader and possibly to the immigrant. The immigrant removes misshapen objects from the belt and places them in a receptacle. The monotony of this work is accentuated by the fact that it is presented in twenty panels of similar composition that show the immigrant watching the belt and occasionally placing a warped object in the receptacle. At this job the man is befriended by an older worker who is also an immigrant. This older man tells the immigrant his tale of geographic displacement, which involves a devastating war which destroyed the older man's home and robbed him of one of his legs. After work, the older man leads the immigrant into the countryside, where they meet some of the older man's friends and play a game involving strange objects and drawings on the ground. As the panels progress, 
the reader is shown that the game is something like a more complicated version of bocce. This sequence of after-work companionship and fun concludes the book's fourth chapter.

\section{Analysis}

Pierce (1985) termed any sign that is tied to its meaning by means of resemblance an "icon", and thus the graphic representations of The Arrival are iconic, in that they are drawings that represent physical realities. Further, Pierce (1985) termed the idea the sign generates in the mind of a reader or hearer the "interpretant" of the sign. In The Arrival, many of the icons generate in the mind of the reader interpretants of an indeterminate nature. The reader is aware that the icon represents a physical reality, whether it be an object or a written symbol, and yet the nature and function of that physical reality remains nebulous. Barthes (1977) famously postulated that images, like words, carry both denotations and connotations. The denotation of an image is the basic meaning of the image (i.e., whatever the image represents) while the connotation involves the cultural implications of the image. In the case of the icons of unfamiliar things in The Arrival, the reader is lacking knowledge of both denotative and connotative meanings. The reader knows neither the precise nature, nor the cultural implications, of many of the things iconically represented in the novel. Herein lies part of the power of The Arrival. This deployment of unfamiliar icons thrusts readers into a world that is largely foreign to them and helps them not only see what the immigrant character sees, but also feel what he feels: sensations of uncertainty, curiosity, and wonder. The use of such unfamiliar icons within graphic narratives may then be seen as a means of cultivating empathy for characters experiencing the bafflements and obscure beauties of life. The use of these icons could also conceivably be used in graphic narratives to convey a sense of the satisfactions of discovery, as the purposes and nature of certain murky icons are eventually illumined through the narrative.

This semiotics of unfamiliarity has potential theoretical applications beyond graphic narratives. In any form of communication, the use of unfamiliar icons could lead to experiences of uncertainty and doubt - and experiences of dawning understanding and discovery. There are manifold potential applications of this notion for visual artists working in any media, and for writers and advertisers. The semiotics of unfamiliarity presents the potential for much future investigation in many domains of communication research.

The semiotics of unfamiliarity is used in The Arrival in the service of creating a rich and compelling narrative about the immigrant experience. The narrative paradigm (Fisher, 1978; 1984; 1985a; 1985b; 1989a; 1989b) recognizes stories as vehicles of rhetorical action, and offers a method by which to evaluate their rhetorical effectiveness. According to the method, a narrative is evaluated on the basis of (1) narrative probability, which refers to the story's 
coherence; and (2) narrative fidelity, which refers to the logic of the story's inherent (and often implicit) argument(s), and the moral values that the story explores and encourages people to embrace and live out (Fisher, 1984; 1985a; 1989). A rhetorically successful narrative, according to this paradigm, is therefore one that is coherent, that makes a sound argument (even tacitly), and that presents and encourages the adoption and implementation of good values.

The narrative probability of the work-related scenes in The Arrival is sound. The graphic novel's presentation of the immigrant's work-related experiences is entirely coherent, even if certain cultural elements of his experiences remain ambiguous. The sequential images of the book make clear that the man is searching for work. His failures and successes on the job hunt, as described above, are easy to comprehend. This success in terms of narrative probability is all the more impressive given the absence of words in the narrative.

The Arrival's work sequences are also successful in terms of narrative fidelity. The story excellently illustrates some of the many difficulties facing immigrants who seek to work in their new countries. These difficulties, as revealed in the narrative, include inexperience with the written symbols of the new country; geographic ignorance and confusion; and a lack of knowledge concerning the material culture of the new country. At the end of the graphic novel's fourth chapter, the fellowship that is offered to the immigrant by the older man and the older man's friends is especially moving. This concluding sequence reminds the reader that, in the face of a new life in an unfamiliar place and a new job that is tedious and unfulfilling, good friends - and some fun - are most welcome. The story thus implicitly argues that immigrants face many potential issues when they move to a new country; that these issues can present problems for them as they seek to procure a new job and begin to work; and that people should be patient, helpful, and friendly with immigrants to help them succeed professionally and personally. The underlying values that The Arrival implicitly encourages the reader to embrace and implement thus include empathy, patience, understanding, helpfulness, and friendliness; these are estimable principles that are of great importance in our globalizing world.

\section{Conclusion}

Deploying what is termed in this paper a semiotics of unfamiliarity, The Arrival cultivates understanding of and empathy for the immigrant experience. The narrative of the book succeeds as rhetoric according to the narrative paradigm, in that the book presents a coherent narrative with sound implicit arguments and good values. The book is thus one of exceptional rhetorical power: through a unique semiotic approach and an engaging and effective narrative, The Arrival demonstrates the work-related struggles of immigrants and encourages readers to help them. 
The Arrival has been used effectively in classrooms for educational purposes (Rhoades et al. 2015; Pantaleo \& Bomphray, 2011), and it could also be used as an assigned reading in organizations in which immigrants are employed. People at all institutional levels who work with immigrants could benefit greatly from reading The Arrival. An official treatise or handbook concerning immigrants in organizations is certainly helpful; but an involving narrative that implicitly argues for the importance of helping immigrants overcome the difficulties they face, and that stirs up empathic sensations, could help everyone in an organization arrive at a better place: a place where immigrants are helped to flourish, and all benefit as a result. 


\section{References}

1.Barthes, R. (1977). Image - Music - Text (S. Heath, Trans.). New York: Hill and Wang.

2.Bjartveit, C. J., \& Panayotidis, E. L. (2014). Pointing to Shaun Tan's The Arrival and re-imagining visual poetics in research. Contemporary Issues in Early Childhood, 15(3), 245-261.

3.de Castro, A. B., Fujishiro, K., Sweitzer, E., \& Oliva, J. (2006). How Immigrant Workers Experience Workplace Problems: A Qualitative Study.

Archives of Environmental \& Occupational Health, 61(6), 249-258.

4.Fisher, W. R. (1978). Toward a logic of good reasons. Quarterly Journal of Speech, 64(4), 376-384.

5.Fisher, W. R. (1984). Narration as a human communication paradigm: The case of public moral argument. Communications Monographs, 51(1), 1-22.

6.Fisher, W. R. (1985a). The narrative paradigm: An elaboration. Communications Monographs, 52(4), 347-367.

7.Fisher, W. R. (1985b). The narrative paradigm: In the beginning. Journal of Communication, 35(4), 74-89.

8.Fisher, W. R. (1989a). Clarifying the narrative paradigm. Communications Monographs, 56(1), 55-58.

9.Fisher, W. R. (1989b). Human communication as narration: Toward a philosophy of reason, value, and action. Columbia, South Carolina: University of South Carolina Press.

10.Foss, S. K. (2005). Theory of visual rhetoric. In K. Smith, S. Moriarty, G. Barbatsis, \& K. Kenney (Eds.), Handbook of visual communication: Theory, methods, and media (141-152). Mahwah, New Jersey: Lawrence Erlbaum.

11.Harrison, D. A., Harrison, T., \& Shaffer, M. A. (2019). Strangers in strained lands: Learning from workplace experiences of immigrant employees. Journal of Management, 45(2), 600-619.

12.Johnston, R.R. (2012). Graphic trinities: languages, literature, and words-inpictures in Shaun Tan's The Arrival. Visual Communication, 11(4), 421-441.

13.Pantaleo, S., \& Bomphray, A. (2011). Exploring grade 7 students' written responses to Shaun Tan's The Arrival. Changing English: Studies in Culture and Education, 18(2), 173-185.

14.Peirce, C. (1985). Logic as semiotic: The theory of signs. In R. Innis (Ed.),

Semiotics: An introductory anthology (pp. 1-23). Bloomington: Indiana University Press. (Original work published 1940)

15.Rhoades, M., Dallacqua, A., Kersten, S., Merry, J., \& Miller, M. C. (2015). The pen(cil) is mightier than the (s)word? Telling sophisticated silent stories using Shaun Tan's wordless graphic novel, The Arrival. Studies in Art Education, 56(4), 307-326.

16.Tan, S. (2006). The Arrival. New York: Arthur A. Levine Books. 
17.Valenta, M. (2008). The workplace as an arena for identity affirmation and social integration of immigrants. Forum: Qualitative Social Research, 9(2), 115 